\title{
CORROSION AND PASSIVITY OF COPPER IN SOLUTIONS CONTAINING SODIUM SULPHIDE. ANALYSIS OF POTENTIOSTATIC CURRENT TRANSIENTS
}

\author{
D. Vasquez Moll, M. R. G. De Chialvo, R. C. Salvarezza and A. J. Arvia
}

Instituto de Investigaciones Fisicoquímicas Teóricas y Aplicadas-INIFTA, Casilla de Correo 16, Sucursal 4, 1900 La Plata, Argentina

(Received 17 October 1984; in revised form 7 January 1985)

\begin{abstract}
A bstract-The electrochemical behaviour of copper electrodes in $\mathrm{NaOH}$ solutions with the addition of $\mathrm{Na}_{2} \mathrm{~S}$ was studied through the analysis of current transients under constant potential and complementary voltammetric and scanning electron microscopy data including energy dispersive $X$-ray analysis.

The overall process can be described by the following three stages. The first stage corresponds to the nucleation and growth of a complex copper sulphide layer at potential values close to the equilibrium potentials of the $\mathrm{Cu} / \mathrm{Cu}_{2} \mathrm{~S}$ and $\mathrm{Cu} / \mathrm{CuS}$ reversible electrodes. The second stage is related to the rupture of the copper sulphide film at potentials more positive than a certain critical value leading to pitting corrosion of copper metal and yielding a pocrly protective copper sulphide layer. The third stage occurs in the copper oxide electroformation range, where the presence of copper sulphide accelerates the electrodissolution of the base metal and copper oxide hinders the sulphidization processes. The current transients of each stage are interpreted through a model based on the nucleation and growth mechanism.
\end{abstract}

\section{INTRODUCTION}

The electrochemical behaviour of copper in solutions containing sulphide ions is very complex as it involves different processes depending on the potential range considered[1]. Thus, at potentials slightly exceeding that of the reversible $\mathrm{Cu} / \mathrm{Cu}_{2} \mathrm{~S}$ electrode the spontaneous formation of copper sulphide layer takes place, through a reaction which is very similar to that for the chemical sulphidization of copper[2], so that to prevent the latter reaction copper must be protected cathodically. The copper sulphide layer exhibits a composite structure where the inner layer consists of a non-stoichiometric compound approaching $\mathrm{Cu}_{2} \mathrm{~S}$ structure and the outer layer, formed under certain circumstances, consists of CuS [3]. When the potential applied to a polycrystulline copper electrode in $1 \mathrm{M}$ $\mathrm{NaHCO}_{3}+0.01 \mathrm{M} \mathrm{Na} \mathrm{Na}_{2} \mathrm{~S}$ exceeds $-0.85 \mathrm{~V}$ (sce) the localized corrosion of copper promoted by the presence of sulphide is noticed[1]. In this potential range large amounts of a poorly adherent crystalline copper sulphide layer results after a prolonged anodizing of copper. When copper is anodized in the potential range where the copper oxide layer is formed the localized corrosion of copper is considerably enhanced, and in this case the sulphidization of copper is greatly inhibited. Furthermore, the presence of copper sulphide delays the formation of the copper oxide layer in the alkaline solution containing sodium sulphide.

This work shows that the complex kinetics of polycrystalline copper electrodes in alkaline solutions containing sodium sulphide can be related to the nucleation and growth of different phases at least in three distinguishable ranges of potentials. In this respect the study is mainly based on the analysis of potentiostatic current transients complemented with voltammetry and scanning electron microscopy.

\section{EXPERIMENTAL}

A single compartment glass made electrolytic cell containing $200 \mathrm{ml}$ of solution was used. The working electrode was made from a copper rod (99.98) included in Araldite, exposing a flat surface of $0.077 \mathrm{~cm}^{2}$ geometric area. The metal surface was firstly mechanically polished with fine grained emery paper, then successively polished with 1 and $0.3 \mu \mathrm{m}$ alumina paste and later, it was rinsed with acetone and twice distilled water. The counter-electrode was a large area platinum plate. The potential of the working electrode was referred to a sce. The latter was connected through a Luggin-Haber capillary tip and a second salt bridge filled with saturated $\mathrm{KNO}_{3}$ to avoid chloride diffusion into the cell (Radiometer K-701).

The sulphide containing alkaline solutions $(0.01 \mathrm{M}$ $\leqq c_{\mathrm{NaOH}} \leqq 0.1 \mathrm{M} ; \quad 0.001 \mathrm{M} \leqq c_{\mathrm{Na}_{2} \mathrm{~S}} \leqq 0.01 \mathrm{M}$ ) were prepared with twice distilled water previously purged with nitrogen during $3 \mathrm{~h}$ and A.R. chemicals (NaOH, $\mathrm{Na}_{2} \mathrm{~S} .9 \mathrm{H}_{2} \mathrm{O}$ ). The solutions were deaerated by nitrogen bubbling during $3 \mathrm{~h}$ prior to the experiments.

The electrode was immersed in the solutions containing sulphides with the potentiostat already turned on at the preset potential $\left(E_{s}\right)$ to avoid spontaneous formation of copper sulphides at open circuit. This procedure was repeated for each measurement and was found to yield reproducible results[4].

A LYP M5 potentiostat together with a LYP GEM4 function generator and a Houston ommigraphic 2000 recorder were used to perform the experiments.

Current transients were also made with copper electrodes anodically polarized firstly in the base solution and immediately afterwards, in the base solution containing sodium sulphide. Runs were made at $25^{\circ} \mathrm{C}$. SEM patterns were pictured from a Philips 500 equipment including the EDAX system. 


\section{RESULTS}

\section{Voltammetric data}

Voltammograms of copper electrodes in $0.1 \mathrm{M}$

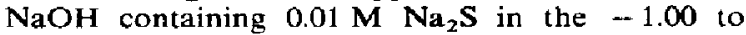
$-0.30 \mathrm{~V}$ potential range at $0.02 \mathrm{~V} \mathrm{~min} \mathrm{mig}^{-1}$ (Fig. 1) show at least three regions. The first region involves an anodic peak (peak I) located at $-0.94 \mathrm{~V}$ which is related to the formation of a black anodic film on the electrode. The second region corresponds to the anodic hump (peak II) appearing at the positive side of peak $I$. When the current reaches the minimum value at $-0.74 \mathrm{~V}$, a black thick adherent salt layer covers the metal surface. At potentials more positive than $-0.74 \mathrm{~V}\left(E_{b}\right)$ a remarkable increase in current and strong current oscillations are observed. In this case, SEM pictures show that the surface of the electrode is already covered by a layer consisting of a poorly adherent black film. The anodized electrode surface after polishing with alumina paste of $0.3 \mu \mathrm{m}$ exhibits pitting corrosion. Finally, the third region located at potentials greater than $-0.50 \mathrm{~V}$, corresponds to the copper oxide electroformation (peak III).

The voltammograms depend considerably on the sodium sulphide concentration (Fig. 1). The increase of the latter results in the increase of heights of peaks I and II and their corresponding peak potentials ( $E_{\mathrm{I}}$ and $E_{\mathrm{II}}$ ) as well as $E_{b}$ shift towards more negative values. $E_{b}$ is related to the breakdown of the anodic film and becomes more negative as the sodium sulphide concentration increases. The $E_{b} v s \log c_{\mathrm{Na}_{2} \mathrm{~s}}$ linear plot has a slope close to $0.06 \mathrm{~V} /$ decade.

To establish the potential range of copper oxide formation in the absence of sulphide ions cyclic voltammograms were run in $0.01 \mathrm{M} \mathrm{NaOH}$ (Fig. 2). In the positive potential going scan, two peaks one at
$-0.30 \mathrm{~V}$ (peak I') and another at $-0.20 \mathrm{~V}$ (peak II') were observed. These peaks correspond to the electroformation of different copper oxides. During the negative potential going scan, these oxides are electroreduced at $-0.30 \mathrm{~V}$ (peak III') and $-0.68 \mathrm{~V}$ (peak IV'), respectively.

\section{Current transients under a constant potential step}

Current transients recorded in $0.1 \mathrm{M} \mathrm{NaOH}$ $+0.01 \mathrm{M} \mathrm{Na} \mathrm{Na}_{2} \mathrm{~S}$ by stepping $E_{s}$ in the -1.00 to $-0.98 \mathrm{~V}$ range show a rapid initial increase in current, to attain later practically a constant value. Otherwise, the current transients run at $-0.97 \mathrm{~V}<E_{\mathrm{s}} \leqslant-0.90 \mathrm{~V}$ show initially a continuous current decrease followed by a current increase up to a maximum $\left(j_{M}\right)$, and finally, a smooth and net decay attaining the stationary current value at $E_{s}$ (Fig. 3). As $E_{s}$ increases $j_{M}$ increases and the time $\left(t_{M}\right)$ to reach $j_{M}$ decreases. However, when $E_{s}>-0.90 \mathrm{~V}$, the current at $t>t_{M}$ either decreases slowly or remains practically constant.

The potentiostatic current transients confirm that various electrochemical processes take place at $E_{s}>$ $-0.90 \mathrm{~V}$. One of them concerns the breakdown of the copper sulphide layer which is related to the rapid increase in current observed at $E_{s}>E_{b}$ in the voltammograms. Under potentiostatic conditions, the breakdown of the copper sulphide film also occurs at potentials lower than $E_{b}$. The more negative $E_{s}$, the greater will be the breakdown time. In this case, two different regions can be distinguished in the current transients (Fig, 4). In region $A$ the current is similar to that already seen in Fig. 3 at low $E_{s}$, and after the corrosion products are removed no pitting of copper is detected. In region $B$, the current transient corresponds to both the breakdown of the adherent
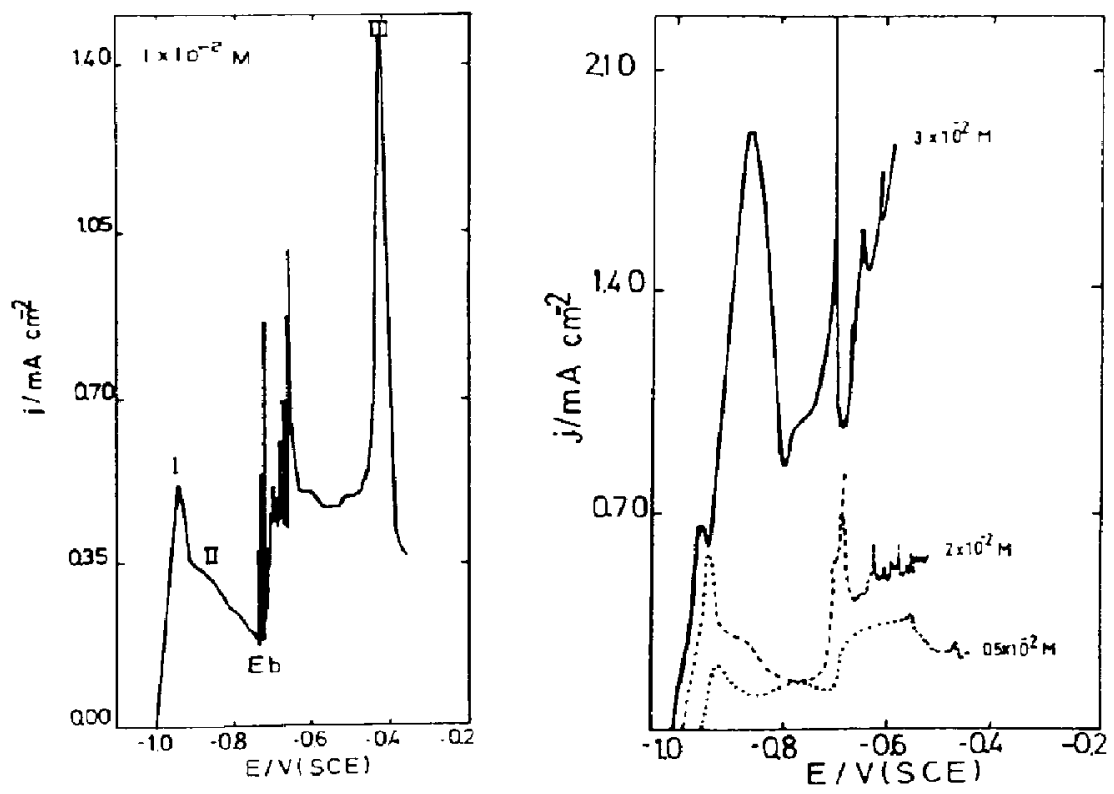

Fig. 1. (E/i) voltammograms of polycrystalline copper in $0.1 \mathrm{M} \mathrm{NaOH}+x \mathrm{M} \mathrm{Na} \mathrm{a}_{2} \mathrm{~S}(0.005 \mathrm{M} \leqq$ $x \leqq 0.03 \mathrm{M}$ ) run at $0.02 \mathrm{Vmin}^{-1}, 25^{\circ} \mathrm{C}$. 


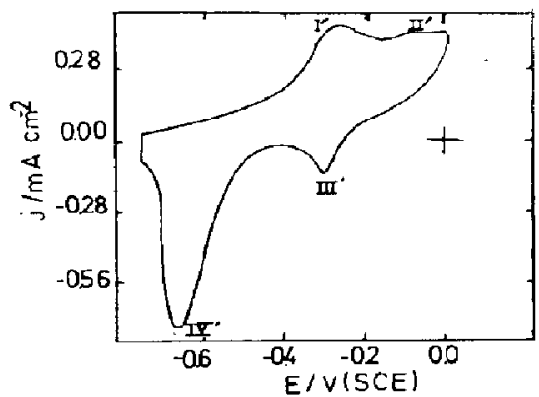

Fig. 2. Typical cyclic voltammogram of polycrystalline copper in $0.01 \mathrm{M} \mathrm{NaOH}$ at $0.01 \mathrm{Vs}^{-1}, 25^{\circ} \mathrm{C}$. The electrode was maintained during $90 \mathrm{~s}$ at $-1.10 \mathrm{~V}$ before the voltammogram was recorded.

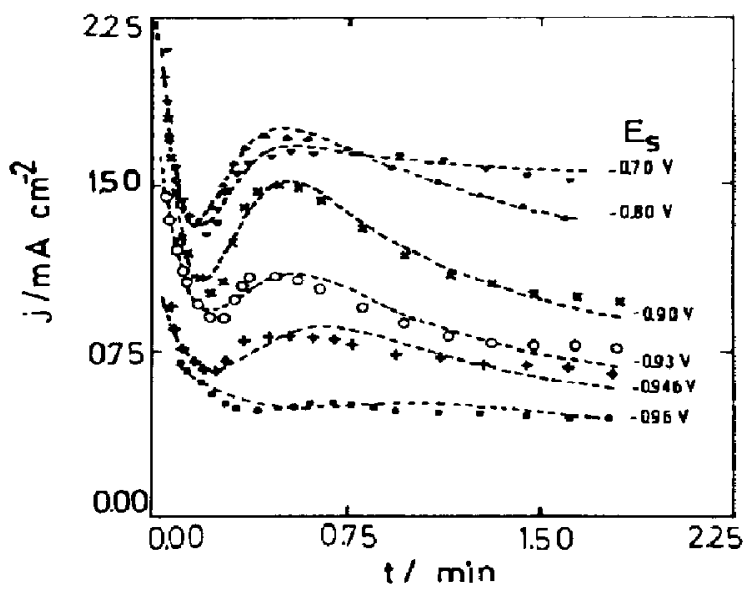

Fig. 3. Current transients of polycrystalline copper recorded at constant potential in $0.1 \mathrm{M} \mathrm{NaOH}+0.01 \mathrm{M} \mathrm{Na}_{2} \mathrm{~S}, 25^{\circ} \mathrm{C}$. The transients were recorded immediately after immersion with the electrode already polarized at the preset potential. The symbols correspond to the experimental data and the dashed lines were computed from Equations (2), (3) and (4).

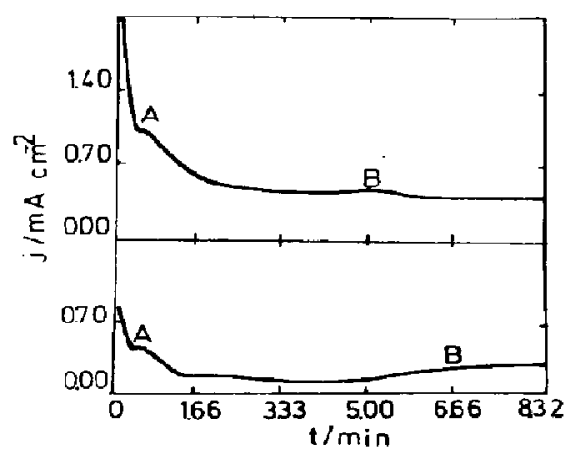

Fig. 4. Current transients of polycrystalline copper in $0.1 \mathrm{M}$ $\mathrm{NaOH}+0.01 \mathrm{M} \mathrm{Na} \mathrm{S}_{2}, 25^{\circ} \mathrm{C}$. Experimental conditions as Fig. 3. sulphide film and the formation of a poorly protective copper sulphide with the simultaneous occurrence of small pits. Region $B$ tends to overlap region $A$ as the potential applied to the electrode is more positive.

Current transients under a constant potential step with copper electrodes preanodized in $0.01 \mathrm{M} \mathrm{NaOH}$

Current transient were firstly recorded in $0.01 \mathrm{M} \mathrm{NaOH}$. In this case the copper electrode was stepped from $-1.10 \mathrm{~V}$ to an $E_{s}$ value in the $-0.60 \mathrm{~V}$ $<E_{s}<0.00 \mathrm{~V}$ range. The corresponding potentiostatic current transients exhibit a continuous decrease for $E_{\mathrm{s}}<0.40 \mathrm{~V}$. At $E_{\mathrm{s}}>-0.40 \mathrm{~V}$, a hump related to the copper oxides electroformation is detected. Experiments were made with copper electrodes previously anodized during $400 \mathrm{~s}$ at $E_{s}$ in the $-0.60 \mathrm{~V}$ $<E_{s}<0.00 \mathrm{~V}$ range in $0.01 \mathrm{M} \mathrm{NaOH}$. Immediately after sulphide was added $(t=0)$ to the $0.01 \mathrm{M} \mathrm{NaOH}$ to reach a preset bulk sodium sulphide concentration in $0.001 \mathrm{M}$ to $0.01 \mathrm{M}$ range. The corresponding current transient at $E_{s}=-0.60 \mathrm{~V}$ results in an instantaneous and remarkable current increase followed by a current decrease to a minimum (Fig. 5). At this point, the electrode surface becomes covered by a black film. Further on, the current rises to reach a maximum and finally, decreases slowly to attain a stationary value at $E_{3}$. This current transient is accompanied by the random rupture of the film in several regions and its detachment from the metal surface into the cell. The current transient at $E_{s}=-0.40 \mathrm{~V}$ results in a current behaviour similar to that described at $E_{s}=-0.60 \mathrm{~V}$, although the current related to the breakdown of the film decreases. When the preanodizing of the copper electrode is made at either -0.10 or $0.00 \mathrm{~V}$, the sodium sulphide addition results in the partial coverage of the electrode surface with a black film. As $E_{s}$ becomes more positive, larger times and small currents related to the film breakdown are observed. At constant $E_{s}$, the latter increases with the concentration of sodium sulphide.

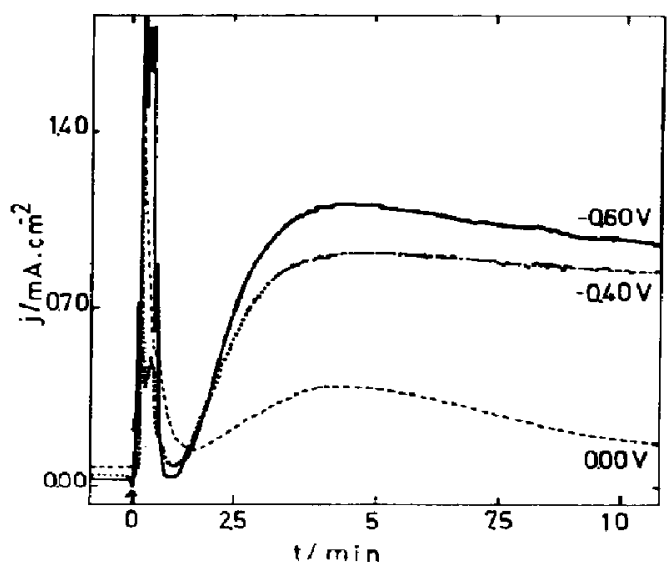

Fig. 5. Current flow at polycrystalline copper at different $E_{s}$ recorded after sodium sulphide addition to $0.01 \mathrm{M} \mathrm{NaOH}$. The electrode was previously anodized at $E_{s}$ during $400 \mathrm{~s}$ before the addition of sodium sulphide to the base $\left(c_{\mathrm{Na}, \mathrm{s}}\right.$ $=0.01 \mathrm{M}$ ). The arrow indicates the sulphide addition $(t=0)$. 
When the copper electrode is anodized at $-0.80 \mathrm{~V}$ in $0.01 \mathrm{M} \mathrm{NaOH}+0.01 \mathrm{M} \mathrm{Na}_{2} \mathrm{~S}$ to form the copper sulphide film and afterwards it is stepped to $E_{s}$ $\left(-0.70 \mathrm{~V} \leqslant E_{s} \leqslant-0.35 \mathrm{~V}\right)$, the current transient shows a sharp decrease to approach a constant value. The latter increases slightly as the applied potential becomes more positive. At potentials close to current peak II', the electroformation of copper oxide takes place.

\section{EDAX data}

The EDAX analysis of the film formed after anodizing the copper electrode at $-0.90 \mathrm{~V}$ during $10 \mathrm{~min}$ in $0.3 \mathrm{M} \mathrm{NaOH}+0.01 \mathrm{M} \mathrm{Na} 2 \mathrm{~S}$ shows the presence of the copper and sulphur signals. Quantitative analysis of the film favours the cuprous sulphide stoichiometry.

\section{DISCUSSION}

The voltammetric results of copper in base solutions containing sodium sulphide show a multiplicity of anodic and cathodic current peaks related to already well established electrochemical reactions[1]. This allows a reasonable interpretation of the current transients run under a constant potential step and the evaluation of the various contributions participating in the copper anodization in alkaline sulphide solution. When the positive potential going scan starts from a potential sufficiently low to prevent copper sulphidization, the first process corresponds to the formation of an initial thin $\mathrm{Cu}_{2} \mathrm{~S}$ layer which probably comprises at the very early stage a non-stoichiometry such as $\mathrm{Cu}_{1.8} \mathrm{~S}[5,6]$. The cuprous sulphide formation is assigned to the decreasing portion of the current transients recorded in the potential range of peaks I and II (Fig. 1). The influence of the double layer charge in the current transients appears at times shorter than those recorded. The current maximum suggests that nucleation and growth process is involved in the current transient behaviour. The corresponding process is the formation of another copper sulphide layer on the initial cuprous sulphide leading to a thick and adherent complex copper sulphide film. As the current maximum is detected at potentials close to the equilibrium potential of the $\mathrm{Cu} / \mathrm{CuS}$ reversible electrode[7], it is reasonable to assume that the film resulting from the nucleation and growth mechanism is mainly cupric sulphide. This reaction probably occurs at the pores of the $\mathrm{Cu}_{2} \mathrm{~S}$ layer[7] and it results in certain degree of passivation. The rupture of this layer yields a poorly adherent CuS layer and pitting corrosion of the base metal. These two processes depend on the concentration of the sodium sulphide, the potential applied to the electrode and the anodizing time. Finally, in the presence of sodium sulphide the electroformation of copper oxide (peak III) is delayed, and simultaneously the electrodissolution of copper is strongly accelerated, although the presence of copper oxide on the metal surface hinders the sulphidization process. Obviously, in the presence of sodium sulphide no soluble copper ion species usually found in the electrooxidation of copper in base[8] can be detected.

The instantaneous average anodic current $\left(j_{t}\right)$ can be taken as the sum of three partial currents, namely that of the formation of the $\mathrm{C} \mathbf{u}_{2} \mathrm{~S}$ layer $\left(j_{I}\right)$, the CuS layer $\left(j_{11}\right)$ and the corrosion of the base metal $\left(j_{c}\right)$. Thus,

$$
j_{t}=j_{\mathbf{I}}+j_{\mathbf{I T}}+j_{\mathrm{c}} \text {. }
$$

The growth of the initial layer occurs at potentials only slightly more positive than the reversible potential of the $\mathrm{Cu} / \mathrm{Cu}_{2} \mathrm{~S}$ electrode and from voltammetry it appears as a diffusion controlled electrochemical reaction [1] involving the formation of a new phase on the electrode surface. The current transient can be interpreted in terms of an instantaneous nucleation and circular bidimensional growth under diffusion control[9]. The instantaneous value of $j_{I}$ is given by an expression of the form

$$
j_{\mathrm{I}}=P_{1} \exp \left(-P_{2} \iota\right) \text {, }
$$

where $\boldsymbol{P}_{1}=q_{\operatorname{mon}} \pi k_{e} D N_{0}$ and $\boldsymbol{P}_{2}-\pi k_{e} D N_{0}, D$ is the diffusion coefficient of the reacting species, $q_{\text {mon }}$ is the charge density required for the full coverage of the metal surface with a cuprous sulphide layer of constant thickness, $k_{\mathrm{e}}$ is a proportionality constant and $N_{0}$ is the number of sites for nucleation available at the metal surface.

On the other hand, the formation of the cupric sulphide layer implies a relatively large charge, depending on the time the potential is held in this range. This fact together with the diffusional characteristics of the corresponding voltammetric peak [1] indicate that the current transient under a constant potential step is probably determined by the rate of progressive nucleation and tridimensional growth under diffusion control $[4,10]$. In this case, the corresponding instantaneous rate equation becomes

$$
j_{11}=\frac{P_{3}}{\sqrt{t}}\left[\left\{1-\exp \left[-P_{4}\left(t-1 / P_{5}\right)^{2}\right]\right\}\right.
$$

where $P_{3}=z F D^{1 / 2} c_{0} / \pi^{1 / 2}, P_{4}=\pi N_{0} \alpha K_{e}^{\prime} D$ and $1 / P_{5}$ $=t_{i}, c_{0}$ is the concentration of the diffusing species, $K_{e}^{\prime}$ is a proportionality constant, $\left(\alpha N_{0}\right)$ is the nucleation rate and $t_{i}$ is the induction time.

Finally, the corrosion of the base metal $\left(i_{c}\right)$ can be associated with the formation of a poorly protective copper sulphide layer during the pitting corrosion of copper. As already established, for this type of process at other corroding metals [11-13] the corresponding rate equation is tentatively related to an instantaneous nucleation and conical growth under charge transfer control[14]. The instantaneous current for such a process is given by the equation:

$$
j_{c}=P_{6}\left[1-\exp \left(-P, t^{2}\right)\right],
$$

where $P_{6}=2 F k_{3 c}^{\prime}$ and $P_{t}=M^{2} k_{3 c}^{2} \pi N_{0} / \rho^{2}$, where $k_{3 c}$ and $k_{3 c}^{\prime}$ are the formal rate constants for the layer growth in the directions parallel and perpendicular to the metal plane respectively, $M$ is the molecular weight and $\rho$ is the salt density.

At short anodization times and low $E_{s}$ values ( $-0.96 \mathrm{~V} \leqq E_{s} \leqq-0.90 \mathrm{~V}$ ), the contribution of $j_{c}$ can be negleeted. In this case, the overall current transient becomes the sum of only two contributions, namely:

$$
i_{t}=i_{1}+i_{\mathrm{I}} \text {. }
$$

In this case, the current transients can be simulated with Equations (2) and (3) (Fig. 3) by using the parameters assembled in Table 1

The ratio $P_{1} / P_{2}$ is equal to the charge required to 
Table 1. Kinetic parameters used in simulation of current transients obtained at $-0.96 \mathrm{~V}$ $\leqslant E_{s} \leqslant 0.90$

\begin{tabular}{lccccc}
\hline$E /(\mathrm{V})$ & $P_{1} /\left(\mathrm{mA} \mathrm{cm}^{-2}\right)$ & $P_{2} /(\mathrm{min})$ & $P_{3} /\left(\mathrm{mA} \mathrm{min}^{1 / 2} \mathrm{~cm}^{-2}\right)$ & $P_{4} /\left(\mathrm{min}^{-2}\right)$ & $P_{5} /(\min )$ \\
\hline-0.96 & 0.832 & 1.78 & 0.538 & 1.32 & 10.4 \\
-0.946 & 1.24 & 4.36 & 0.763 & 4.96 & 17.0 \\
-0.93 & 2.17 & 5.78 & 0.898 & 7.64 & 16.0 \\
-0.90 & 3.18 & 8.29 & 1.21 & 10.0 & 15.5 \\
\hline
\end{tabular}

form a complete layer of cuprous sulphide on the electrode. Therefore, the average layer thickness can be estimated from the following relationship:

$$
h=\frac{M}{2 F_{\mu}} \frac{P_{1}}{P_{2}} .
$$

Taking for cuprous sulphide $\rho=5.6 \mathrm{~g} \mathrm{~cm}^{-3}, M$ $=159.2 \mathrm{~g} \mathrm{~mol}^{-1}$ and $z=2$, the estimated value of $h$ is between 0.025 and $0.05 \mu \mathrm{m}$. This figure suggests that a tridimensional rather than a bidimensional cuprous sulphide layer is formed.

On the other hand, the kinetics of the formation of the cupric sulphide adherent layer becomes controlled by sulphide ion diffusion from the solution[1], the present approach offers the possibility of evaluating the diffusion coefficient of sulphide ion from the value of $P_{3}$ by using the following relationship:

$$
D=\left(P_{3} \pi^{1 / 2} / z F c_{0}^{e}\right)^{2} \text {, }
$$

where $c_{0}^{e}=c_{0}^{b} \exp (z F \phi / R T), c_{0}^{e}$ and $c_{0}^{b}$ are the concentrations of the reacting species at the electrode surface and in the bulk of the solution, respectively, when the potential $\phi$ is applied to the electrode. It should be noticed that $P_{3}$ exhibits a slight dependence on the applied potential through the $c_{0}^{c}$ value. If the latter correction is taken into account, then the value of $D$ resulting from $c_{0}^{b}=10^{-5} \mathrm{~mol} \mathrm{~cm}^{-3}$ and $z=2$, is $D$ $=1.3 \times 10^{-5} \mathrm{~cm}^{2} \mathrm{~s}^{-1}$.

An estimation of the nucleation rate $\left(\alpha N_{0}\right)$ can also be made from the values of $P_{4}$ and $D$, according to the relationship:

$$
\left(\alpha N_{0}\right)=3 P_{4} \rho^{1 / 2} /\left[4\left(8 \pi c_{0} M\right)^{1 / 2} D\right] .
$$

On the assumption that the anodic layer consists mainly of cupric sulphide, for $c_{0}^{b}=10^{-5} \mathrm{~mol} \mathrm{~cm}^{-3}$, $\rho=4.76 \mathrm{~g} \mathrm{~cm}^{-3}$ and $M=95.63 \mathrm{~g} \mathrm{~mol}^{-1}$, values of $\left(\alpha N_{0}\right)$ at different potentials are obtained (Table 2). In

Table 2

\begin{tabular}{lc}
$E /(\mathrm{V})$ & $\alpha N_{0}\left(\mathrm{~s} \mathrm{~cm}^{2}\right)$ \\
\hline-0.96 & 298 \\
-0.946 & 1120 \\
-0.93 & 1725 \\
-0.90 & 2249 \\
\hline
\end{tabular}

the potential range of the electroformation of the adherent cupric sulphide layer, the nucleation rate changes with potential according to the following relationship (Fig. 6):

$$
\alpha N_{0}=K_{1} \exp \left[-K_{2} /\left(E_{s}-E_{n}\right)\right] \text {. }
$$

This equation is already well established for the overpotential dependence of nucleation rate[15]. From the slope of the In $\left(\alpha N_{0}\right)$ vs $1 /\left(E-E_{n}\right)$ linear plot (Fig. 6) $K_{2}$ is obtained and from $K_{2}$ the number of atoms in the critical nuclei $\left(g^{*}\right)$ can be estimated. Consistent values of $g^{*}$ result only at low potential values, that is in the potential range where the interference of pitting is negligible. When the applied potential increases due to the increasing contribution of pitting the number of sites available for the adherent cupric sulphide nucleation should decrease. This change is probably balanced by the increases of $\alpha$ with the applied potential, so that the $\alpha N_{0}$ value increases only slightly with the applied potential and, correspondingly, low $K_{2}$ values are observed.

At $E_{\mathrm{s}}>-0.90 \mathrm{~V}$, the nucleation and growth of the copper sulphide complex layer and the rupture of the layer occur simultaneously. Consequently, the contribution of $j_{c}$ must be considered. In this case, the current transients can be reproduced by means of Equations (2), (3) and (4) (Fig. 3). The simulation parameters are assembled in Table 3.

The various current contributions entering in these current transients are depicted in Fig. 7. As

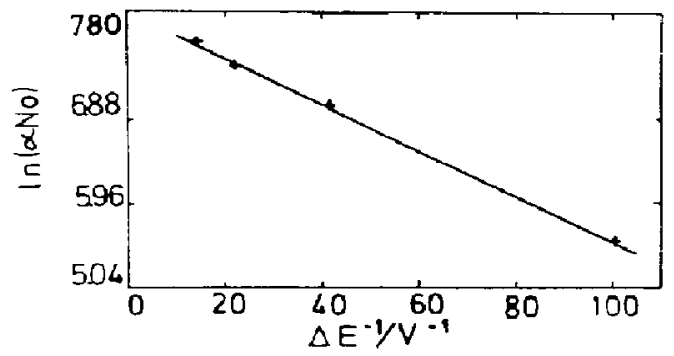

Fig. 6. Dependence of $\ln \left(\alpha N_{0}\right)$ on $1 /\left(E_{s}-E_{n}\right) \quad E_{n}=$ $-0.97 \mathrm{~V}$.

Table 3. Kinetic parameters used in simulation of current transients obtained at $E_{s}>-0.90 \mathrm{~V}$

\begin{tabular}{cccccccc}
\hline$E /(\mathrm{V})$ & $P_{1} /\left(\mathrm{mA} \mathrm{cm}^{-2}\right)$ & $P_{2} /(\min )$ & $P_{3} /\left(\mathrm{mA} \mathrm{min}^{1 / 2} \mathrm{~cm}^{-2}\right)$ & $P_{4} /\left(\mathrm{min}^{2}\right)$ & $P_{5} /(\mathbf{m i n})$ & $P_{6} /\left(\mathrm{mA} \mathrm{cm}^{-2}\right)$ & $P_{5} /\left(\mathrm{min}^{2}\right)$ \\
\hline-0.88 & 3.28 & 7.22 & 1.29 & 8.73 & 15.5 & 0.0168 & 2.59 \\
-0.80 & 3.14 & 7.25 & 0.997 & 13.2 & 16.7 & 0.570 & 4.01 \\
-0.70 & 3.60 & 8.47 & 0.248 & 11.2 & 19.7 & 1.37 & 12.4 \\
- & & & & &
\end{tabular}




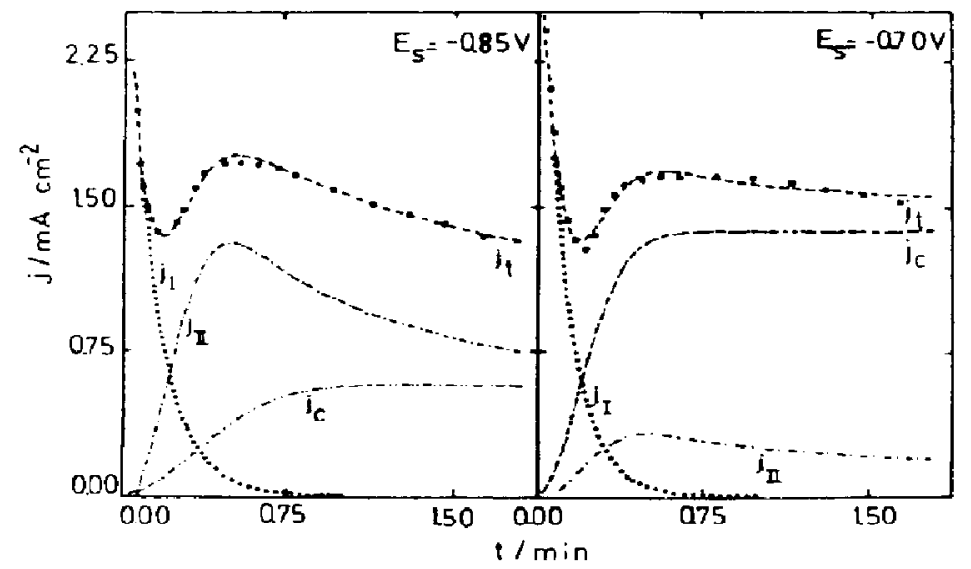

Fig. 7. Current transients of polycrystalline copper recorded at $E_{\mathrm{s}}=-0.85 \mathrm{~V}$ and $E_{\mathrm{s}}=-0.70 \mathrm{~V}$ calculated with Equations (2), (3) and (4). The symbols correspond to the experimental data and the dashed lines are computed as the sum of three contributions. Experimental conditions as Fig. 3.

$E_{s}$ increases $j_{\mathrm{II}}$ decreases, and $\left(j_{c}\right)$ pitting corrosion of the base metal is enhanced. Both $P_{6}$ and $P_{7}$ show a marked dependence on the applied potential. The decrease in the amount of $j_{\mathrm{II}}$ during pitting explains the EDAX results showing mainly that a cuprous sulphide layer appears on the metal surface due to the poorly adherent characteristics of the cupric sulphide films formed during pitting.

The complex nature of processes discussed in the present paper indicates that one should be critical on the relevance of the conclusions derived from the different adjusting parameters used in the reaction model. Nevertheless, at potentials where the contributions of each process becomes independent of the others, the magnitudes derived from the fitting parameters are coherent and physically meaningful.

Acknowledgements-INIFTA is a research institute jointly established by the Universidad Nacional de La Plata, the Consejo Nacional de Investigaciones Cientificas y Técnicas and the Comisión de Investigaciones Cientificas de la Provincia de Buenos Aires. This work was also partially sponsored by the Regional Program for the Scientific and Technological Development of the Organization of the American States.

D. V. M. acknowlcdges the fellowship granted by the Deutscher Akademischer Austauschdicnst, through the University of Mainz-University of La Plata Cooperation Agreement.

\section{REFERENCES}

1. M. R. G. de Chialvo and A. J. Arvia, J. uppl. Electrochem. (in press).

2. T. P. Hoar and A. J. P. Tucker, J. Inst. Metals 81, 665 (1952).

3. E. M. Kahiry and N. A. Darwish, Corros. Sci. 13, 141 (1973).

4. B. Scharifker, R. Regules and J. Mozota, Electrochim. Acta 29, 261 (1984).

5. M. Lamache and D. Baner, Anal. Chem, 51, 1320 (1979).

6. B. C. Syrett, Corrosion 33, 257 (1977).

7. E. M. Kahiry and N. A. Darwish, Corros. Sci. 13, 149 (1973).

8. M. R. G. de Chialvo. S. L. Marchiano and A. J. Arvia, J. appl. Electrochem. 14, 165 (1978).

9. W. Davison and J. A. Harrison, J. electroanal. Chem. 44, 213 (1973).

10. B. Scharifker and G. Hill, Electrochim. Acta 28, 879 (1983).

11. D. V. Vasquez Moll, R. C. Salvarezza, H. A. Videla and A. J. Arvia, Corrosion 40, 414 (1984).

12. D. V. Vasquez Moll, R. C. Salvarezza, H. A. Videla and A. J. Arvia, Carros. Sci. 24, 751 (1984).

13. D. V. Vasquez Moll, R. C. Salvarezza, H. A. Videla and A. J. Arvia, $J$. electrochem. Soc (in press).

14. M. Y. Abyanch and M. Fleischmann, Electrochim. Acta 27, 1513 (1982).

15. T. Erdey-Gruz and M. Volmer; Z phys. Chem. A 157, 165 (1931). 